\title{
SEM/EDS-Assisted LAM-ICPMS Analyses of Tourmaline of Tourmalinites Hosted in Serpentinites of the Paso Del Dragón Complex, Northeastern Uruguay
}

\author{
Gianna M. Garda ${ }^{1}$, Sandra Andrade ${ }^{1}$ and Elena Peel-Canabal ${ }^{2}$ \\ 1. Dept. Mineralogy and Geotectonics/Geosciences Institute, São Paulo University, São Paulo, Brazil \\ 2. Dept. Internal Geodynamics/Geosciences Institute, University of the Republic, Montevideo, Uruguay
}

The Cerro La Tuna (NE Uruguay) is composed of deformed and metamorphosed mafic-ultramafic rocks of Neoproterozoic age. Serpentinites predominate and are associated with magnesian schists, banded micaceous schists and quartzites, and amphibolitic schists. Tourmalinite occurs as boudins in the serpentinites and is composed of radiating fans of acicular, $\mathrm{cm}$-long tourmaline and chlorite [1].

Tourmaline has successfully been applied in the interpretation of geologic processes. Thanks to certain characteristics, tourmaline can acquire a chemical signature from the rock in which it develops and can retain that signature through geologic time [2]. As a contribution to the understanding of the still debatable origin of Paso del Dragón Complex mafic-ultramafic rocks [3, 4], we started a SEM/EDSassisted LAM-ICPMS study of the Cerro La Tuna tourmaline, aiming at its chemical characterization.

LAM-ICPMS study requires a 80 micron-thick polished thin section, which was coated with carbon for the preceding SEM/EDS session. A scanning electron microscope LEO 4401 coupled with an Oxford Inca EDS system was used for the acquisition of back-scattered electron (BSE) images and semiquantitative EDS analyses of major elements in tourmaline and identification of accessory minerals (very bright phases in Fig. 1).

The carbon coating was removed from the thin section and the spots in tourmaline analyzed by EDS were mapped, in order to perform the LA-ICPMS analyses as close as possible to the EDS analyses. The mass spectrometer Thermo Scientific iCAP Q used in this study is coupled with a New Wave Research UP-213 laser ablation system. Laser ablation of internal spots in tourmaline (e.g. P2-c4 and P2-4b in Fig. 1) was performed with a 65-micron laser-spot diameter, 85\% laser power, 5-micron depth and 10 $\mathrm{Hz}$ repetition rate. Analyses along tourmaline rims (e.g. P2-r4 in Fig. 1) were performed in raster mode, adopting 70\% laser power, 2 micron/sec scanning speed, 5-micron depth, and 25-micron spot size. Laser-sample interaction time was $60 \mathrm{sec}$, preceded by a 60 -sec analysis of blank. Glitter 4.4.2 software aided on-line correction of instrumental drift, fractionation and data reduction.

All element concentrations were normalized using $\mathrm{Mg}$ as an internal standard. As revealed by BSE images and EDS analyses, darker gray areas in tourmaline (Fig. 1) correspond to higher Mg contents and the $\mathrm{MgO}$ content used was $11.5 \mathrm{wt} \%$; for brighter gray areas, the $\mathrm{MgO}$ content used was 10.15 wt.\% (EPMA in [1]). Standard NIST-610 was used for calibration and BHVO-2 for quality control.

The advantage of monitoring LAM-ICPMS analyses is the possibility of correction of the data from interferences caused by accessory minerals, such as monazite, Y and Ti oxides (Fig. 1).

Figure 2 shows the compositional variations in brighter and darker areas in tourmaline. Similar variations to graph (a) were obtained for $\mathrm{Al}_{2} \mathrm{O}_{3}$ and $\mathrm{SiO}_{2}$ (EPMA in [1]) and Mn; similar to graph (b), $\mathrm{FeO}$ (EPMA in [1]) and $\mathrm{Zn}$, and to some extent: $\mathrm{Li}, \mathrm{V}$ and $\mathrm{Sr}$. Chondrite-normalized REE concentrations 
are represented in graph (c). The differences in compositional trends for brighter and darker areas indicate variations in the composition of the fluids that generated the Cerro La Tuna tourmalinite.

Our study indicates that at least three types of fluids affected the Cerro La Tuna mafic-ultramafic rocks. One type contributed with B for the formation of Mg-rich tourmaline by interaction (metasomatism) with silicates (e.g., amphiboles, chlorite of the Cerro La Tuna ultrabasic rocks). Another type of fluid (richer in $\mathrm{Ti}, \mathrm{Fe}, \mathrm{Ca}, \mathrm{V}, \mathrm{Sr}, \mathrm{Li}$ and possibly REE) interacted with the Mg-rich tourmaline, generating the brighter grey areas along its rims and fractures. A third type of fluid, from which monazite, Ti and Y precipitated, does not seem to have affected the composition of the preexisting tourmaline, as indicated by its very low REE contents (below MDL in LAM-ICPMS analyses). [5]

\section{References:}

[1] E Peel-Canabal, Ph.D. Thesis, Geosciences Institute, São Paulo University, São Paulo (2012), 198p.

[2] BL Dutrow and DL Henry, Elements 7 (2011), p. 301-306.

[3] RC Ramos and E Koester, Pesquisas em Geociências 41 (2014), p. 25-38.

[4] TM Will et al, Lithos 202-203 (2014), p. 363-381.

[5] The authors wish to thank Dr. IJ Sayeg for BSE image acquisition and EDS analysis of tourmaline and accessory minerals, and Prof. MAS Basei for discussions and contributions to this study.
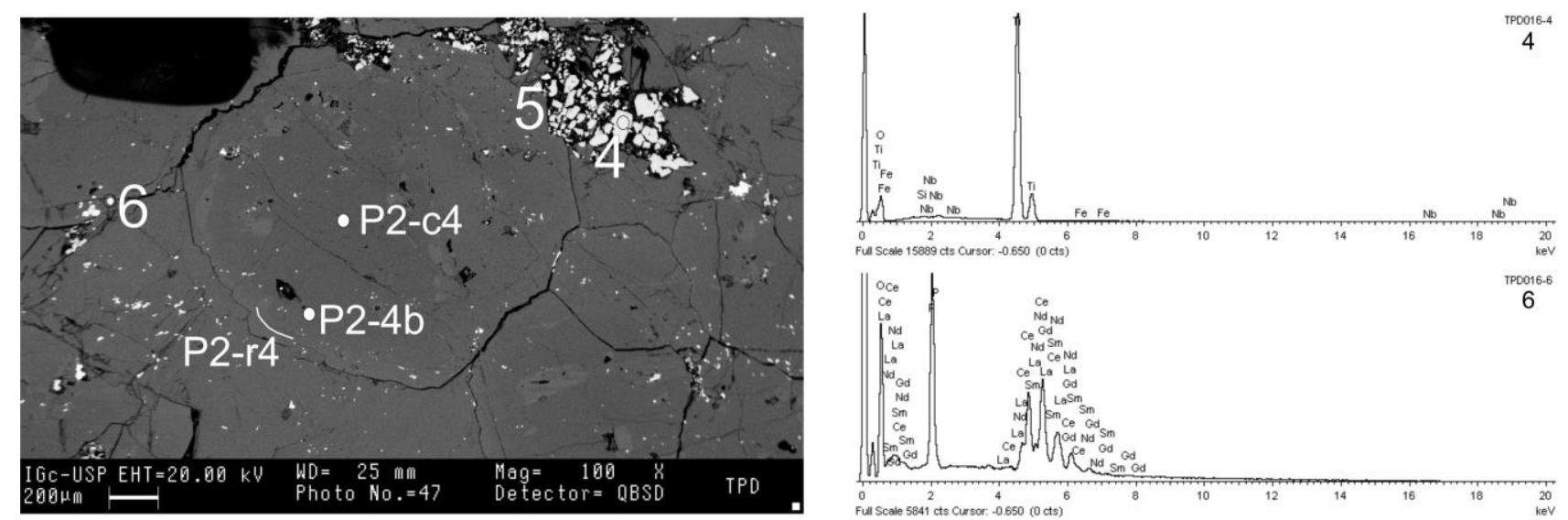

Figure 1. BSE image of the Cerro La Tuna tourmalinite. Brighter gray areas in tourmaline correspond to lower Mg contents, when compared to darker gray areas. Spectra for Ti oxide (4) and monazite (6) correspond to EDS analyses of spots 4 and 6 marked in the BSE image. (5) is Y oxide.
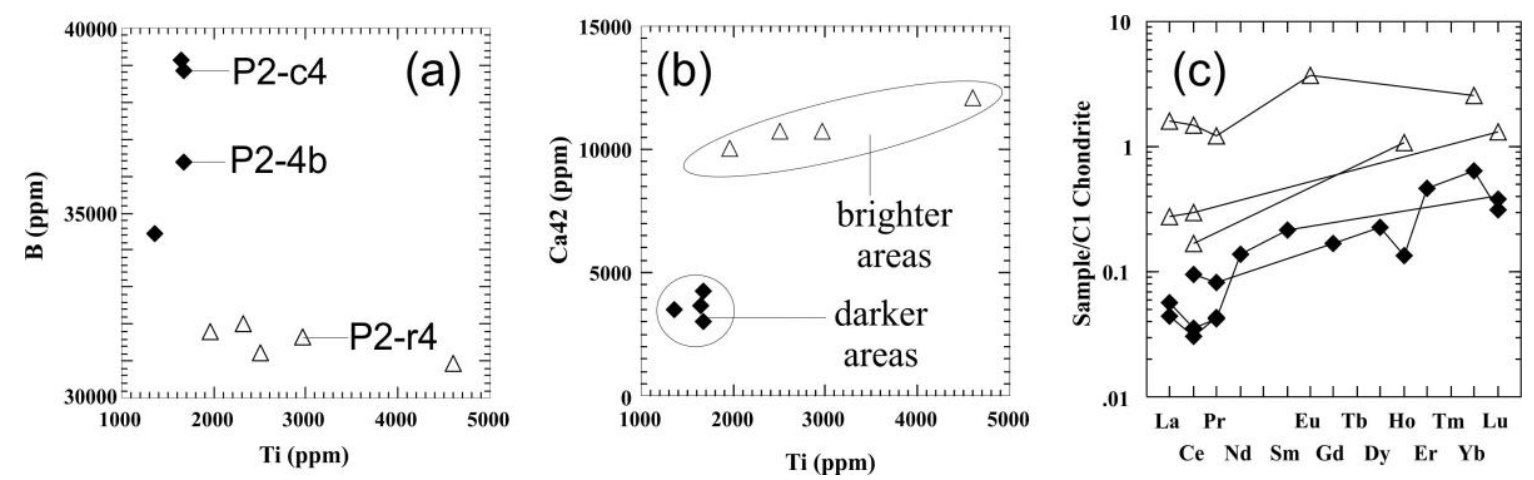

Figure 2. LAM-ICPMS analyses (in ppm) of ligher gray (white triangles) and darker gray areas (black diamonds) in tourmaline. In (a), analyses of P2-c4, P2-4b and P2-r4 are indicated. 